\title{
Feelings of Economic Gain in the Past Blind People to Inequality
}

\author{
Yang Wang, Yi Ding* \\ School of Psychology, Nanjing Normal University, Nanjing, China \\ Email: *yiding2017@hotmail.com
}

How to cite this paper: Wang, Y., \& Ding, Y. (2021). Feelings of Economic Gain in the Past Blind People to Inequality. Advances in Applied Sociology, 11, 377-383. https://doi.org/10.4236/aasoci.2021.118034

Received: July 21, 2021

Accepted: August 7, 2021

Published: August 10, 2021

Copyright $\odot 2021$ by author(s) and Scientific Research Publishing Inc. This work is licensed under the Creative Commons Attribution International License (CC BY 4.0).

http://creativecommons.org/licenses/by/4.0/

\section{(c) (i) Open Access}

\begin{abstract}
The rapid increase of economic inequality is prevalent in many societies, yet people seem to underestimate actual inequality dramatically. In this study, we examine whether and how feelings of economic gain affect people's perceptions of economic inequality in China, a society with the rapid development of the economy after China's reform and opening-up and is now also facing a high level of economic inequality. Using a large Chinese sample, we found that individuals with higher feelings of economic gain reported lower perceptions of economic inequality, and meritocracy beliefs could partially mediate this effect. These findings highlight the importance of personal feelings of economic gain in shapes people's perceptions of economic inequality.
\end{abstract}

\section{Keywords}

Feelings of Economic Gain, Meritocracy, Perceptions of Inequality

\section{Introduction}

Economic inequality, which refers to the unequal distribution of wealth between the top and bottom of the society, has become commonplace around the world (Jencks, 2002; Pickett \& Wilkinson, 2010). Evidence suggests that it relates to lower individual and societal well-being, such as more personal health distress and social conflict (Kawachi et al., 1997; Oishi, Kesebir, \& Diener, 2011). However, people in many societies seem not widespread to concern about rising economic inequality or raise a consensus on redistributive policies aimed at reducing it (Starmans, Sheskin, \& Bloom, 2017). One reason for this is that people may be blind to economic inequality and tend to underestimate the actual level of inequality in their society (Norton \& Ariely, 2011). Indeed, in a national survey, when asking Americans to estimate the actual distribution of wealth in the U.S., they dramatically underestimated actual wealth inequality-they estimated 
the richest $20 \%$ of people would possess about $59 \%$ of the wealth while the actual number is about $84 \%$ (Norton \& Ariely, 2011).

As the rapid increase of economic inequality has received growing public and scientific attention, however, why are some people blind to it? In a recent review article, Ding and Ji (2021) argued that feelings of economic gain, which refers to a positive evaluation of and satisfaction with the current economic situation compared to the past, might contribute to people's underestimation of inequality. To examine this argument, in this research, we test whether and how feelings of economic gain affect people's perceptions of economic inequality in China, a society with the rapid development of the economy after China's reform and opening-up and is now also facing a high level of economic inequality (Xie \& Zhou, 2014).

Using a nationwide representative sample of 28,300 adults from the China Family Panel Studies, Wang and her colleagues (2020) found that most Chinese people have experienced the transition from poverty to riches and hold a great sense of economic gain. And importantly, such sense of gain has been found to be associated with higher levels of life satisfaction and social fairness (Wang \& Liu, 2019). Moreover, Jia and his colleagues (2020) also found that people who get more in their past lives easily evaluate society as fair and positive. Given this evidence, we hypothesize that people with higher feelings of economic gain might consider their society as fair and tend to be insensitive to economic inequality.

Notably, a large body of research highlights the importance of ideology in perceptions of economic inequality (e.g., Rodriguez-Bailon et al., 2017; Jost et al., 2003; Sidanius \& Pratto, 2001). For example, Kraus and colleagues (2017) find that beliefs about societal fairness, like meritocratic beliefs, would predict overestimates of economic equality. Meritocracy refers to a social system in which anyone can get ahead based on hard work and talent (Kluegel \& Smith, 1986). Research shows that people who experience upward class mobility tend to endorse high meritocratic beliefs, such as internal attributions of wealth differences (i.e., ability and effort, e.g., Whyte \& Im, 2014). Building on this work, we predict that meritocracy beliefs may play a mediational role in the association between feelings of economic gain and perceptions of economic inequality.

To summarize, we hypothesize that feelings of economic gain negatively predict perceptions of inequality (Hypothesis 1), and this effect could be mediated by meritocracy (Hypothesis 2). We tested these hypotheses using a large nationwide Chinese sample.

\section{Method}

\subsection{Participants}

699 participants ( $65.4 \%$ male, $34.6 \%$ female; $M=28.61$ years, $S D=7.43$ years) were recruited online through Tencent platform (https://wj.qq.com). All participants joined the study voluntarily with anonymity and confidentiality. They 
were allowed to withdraw at any time during the study.

\subsection{Procedure and Measures}

When participants saw the recruitment information on the Tencent platform, they were told that they would complete some questionnaires regarding their attitudes towards social and economic policy, and they would get 5 Chinese Yuan (CNY; about .7732 US dollars at the time of the study) as a survey reward if they completed the questionnaires and passed the test questions.

Feelings of economic gain. Participants first completed two questions on a 7 -point scale to measure their feelings of economic gain $(\alpha=.907$; i.e., "how do you think of your current economic situation compared to your past? [ $1=$ very bad, 7 = very good]" and "are you satisfied with your current economic situation compared to your past? [ $1=$ most dissatisfied, $7=$ most satisfied]"). Because of the high correlation between the two questions $(\mathrm{r}=.832, p<.01)$, we calculated the average score of them to represent participants' feelings of economic gain, with higher scores indicating higher feelings of economic gain.

Meritocracy. After, participants completed a 10-item meritocratic beliefs scale ( $\alpha=.846$; e.g., "Anyone who is willing and able to work hard has a good chance of succeeding"; Day \& Fiske, 2017) on a 7-point scale ( 1 = strongly disagree, 7 = strongly agree). We calculated the average score to represent participants' level of meritocracy, with higher scores indicating higher levels of meritocracy.

Perceptions of inequality. Afterward, to measure perceived inequality, participants were asked to choose among seven graphs the one that most accurately represented the present situation of income distribution in participants' country (Rodriguez-Bailon et al., 2017; Sánchez-Rodríguez, Willis, \& Rodríguez-Bailón, 2019).

Demographic and control variables. Finally, participants reported their age and gender. We assessed participants' education level on a 5-point scale (1 = elementary school or lower, $2=$ middle school, $3=$ high school, $4=$ junior college or bachelor's degree, 5 = master's degree or higher) and average monthly disposable income on a 11-point scale $(0=$ no personal income, e.g., $0=$ student or other unemployed, $1=$ less than CN¥1000, $2=\mathrm{CN} ¥ 1000-\mathrm{CN} ¥ 3000,3=$ $\mathrm{CN} ¥ 3001-\mathrm{CN} ¥ 5000,4=\mathrm{CN} ¥ 5001-\mathrm{CN} ¥ 7000,5=\mathrm{CN} ¥ 7000-\mathrm{CN} ¥ 10,000,6=$ $\mathrm{CN} ¥ 10,001$ - CN¥15,000, $7=\mathrm{CN} ¥ 15,001-\mathrm{CN} ¥ 30,000,8=\mathrm{CN} ¥ 30,001$ CN¥50,000, 9 = CN¥50,001 - CN¥100,000, $10=$ more than CN¥100,000).

\section{Results}

\subsection{Initial Analyses}

Table 1 shows the descriptive statistics and correlations of the variables in this study. Correlations between feelings of economic gain, meritocracy, and perceptions of inequality were significant in the expected directions. Moreover, we found that we found that feelings of economic gain significantly predict perceptions of inequality $\left(\beta=-.127, p<.001\right.$, effect size $\left.\mathrm{f}^{2}=.015, \Delta \mathrm{R}^{2}=.015\right)$. This effect was still significant even we included income and education as covariates in 
the model $\left(\beta=-.121, p<.05\right.$, effect size $\left.\mathrm{f}^{2}=.012, \Delta \mathrm{R}^{2}=.012\right)$, suggesting that feelings of economic gain lead to lower perceptions of inequality.

\subsection{Mediation Analysis}

To test whether meritocracy beliefs could explain the effect of feelings of economic gain on perceptions of economic inequality, we conducted a mediation analysis with income and education level as covariates using the bootstrapping method based on 5000 bootstrap samples (see Figure 1; Preacher \& Hayes, 2008). This analysis showed that the total effect of feelings of economic gain on perceptions of inequality (total effect $=-.13, p=.002$ ) remain significant when meritocracy was included in the model (direct effect $=-.09, p=.041$ ). Moreover, the indirect effect of feelings of economic gain on perceptions of inequality through meritocracy was significant, $\mathrm{b}=-.04,95 \% \mathrm{CI}[-.07,-.01]$. These findings suggest that higher feelings of economic gain make people blind to inequality could be partly explained by meritocracy.

\section{Discussion}

With the rapid development of the economy after the reform and opening up of China, economic inequality has also been increasing (Xie \& Zhou, 2014). Unlike other countries, most Chinese people have gained great economic benefits in this process. The present study examined whether and how feelings of economic gain cause people to blind inequality. We found that people who have greater feeling of economic gain were more likely to underestimate economic inequality, and

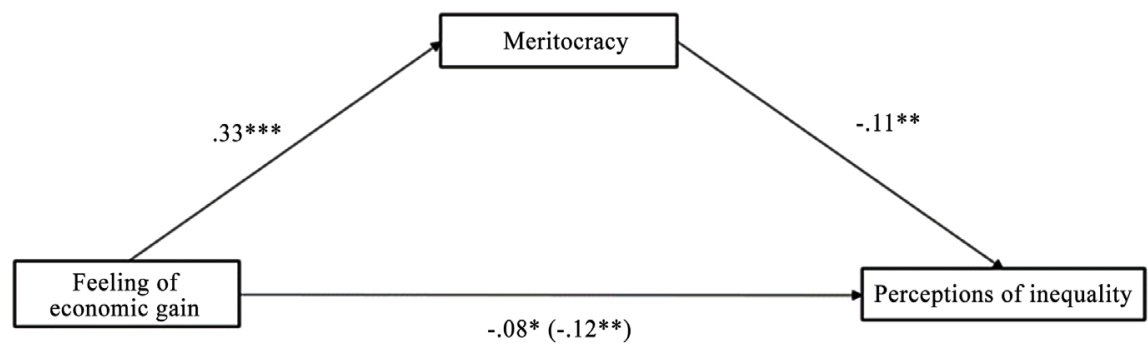

Figure 1. Mediational model of meritocracy on feelings of economic gain and perceptions of inequality. Note: Parameter estimates are standardized regression coefficients $(\beta)$. ${ }^{*} p<.05 .{ }^{* *} p<.01 .{ }^{* * *} p<.001$.

Table 1. Descriptive statistics and correlations among the key variables.

\begin{tabular}{lccccccc}
\hline \multicolumn{1}{c}{ Variable } & $M$ & $S D$ & 1 & 2 & 3 & 4 & 5 \\
\hline 1. Feeling of economic gain & 4.95 & 1.43 & - & & & & \\
2. Meritocracy & 4.92 & .99 & $.33^{* *}$ & - & & & \\
3. Perceptions of inequality & 5.35 & 1.56 & $-.13^{* *}$ & $-.14^{* *}$ & - & & \\
4. Income & 4.16 & 1.62 & $.29^{* *}$ & $.09^{*}$ & -.05 & - & \\
5. Education & 3.68 & .73 & $.17^{\star *}$ & $-.10^{* *}$ & -.04 & $.41^{* *}$ & - \\
\hline
\end{tabular}

Note. $N=699 ;{ }^{*} p<.05 .{ }^{* *} p<.01$. 
this effect was driven by their meritocracy beliefs. These findings highlight the importance of personal feelings of economic gain and how it shapes people's attitudes toward economic inequality.

We should note that there may be some limitations in this study. First, in addition to individual feelings of economic gain at the micro level, the rapid economic development at the macro level may also lead people to underestimate the status quo of inequality. There is a slogan in China that "the rich first lead the rich later", which may cause a large portion of Chinese residents to believe that an increase in economic inequality automatically accompanies economic development and thus is a necessary cost for economic growth (Xie et al., 2012; Xie, 2016), and firmly believe that the relationship between economic development and income inequality takes the form of an inverted $U$ : inequality first increases at the early stages of economic development and then declines in the later stages (Barro, 2000; Chiswick, 1971; Lenski, 1966). Thus, Chinese people blind to inequality might stem from the belief that equality will gradually be achieved.

Second, our study only focused on people's perceptions of economic inequality, but neglected people's attitudes towards inequality. Future research might examine whether and how feelings of economic gain influence people's attitudes and preferences towards economic inequality. Last, with the extraordinary success in reducing poverty and generating economic growth over the last forty years in China, scholars pointed out that Chinese people generally have a high level of sense of gain, not only about their feelings of gain in economic well-being, but also in public service, social equity, and justice (Wang et al., 2020). Future research might test the roles of other aspects of feelings of gain in perceptions of economic inequality.

In summary, the current research tested the effect of economic gain on people's perceptions of economic inequality in China. Higher feelings of economic gain increased underestimations of economic inequality. Hence, our findings suggest that in some rapid economic development societies, economic inequality might be particularly underestimated by residents with higher feelings of economic gain, and this may have negative effect on their attitudes and policy preferences towards redistribution.

\section{Conflicts of Interest}

The authors declare no conflicts of interest regarding the publication of this paper.

\section{References}

Barro, R. J. (2000). Inequality and Growth in a Panel of Countries. Journal of Economic Growth, 5, 5-32. https://doi.org/10.1023/A:1009850119329

Chiswick, B. R. (1971). Earnings Inequality and Economic Development. The Quarterly Journal of Economics, 85, 21-39. https://doi.org/10.2307/1881838

Day, M. V., \& Fiske, S. T. (2017). Movin'on Up? How Perceptions of Social Mobility Affect Our Willingness to Defend the System. Social Psychological and Personality Science, 
8, 267-274. https://doi.org/10.1177/1948550616678454

Ding, Y., \& Ji, T. (2021). Not Fearing Inequality? The Psychological Explanations for Tolerance of Economic Inequality. Journal of Psychological Science, 44, 412-418.

Jencks, C. (2002). Does Inequality Matter? Daedalus, 131, 49-64. https://www.jstor.org/stable/20027737

Jia, Q., Zhou, J., \& Huang, M. (2020). Life Satisfaction Predicts Perceived Social Justice: The Lower Your Life Satisfaction, the Less Just You Perceive Society to Be. Frontiers in Psychology, 11, 3084. https://doi.org/10.3389/fpsyg.2020.540835

Jost, J. T., Pelham, B. W., Sheldon, O., \& Ni Sullivan, B. (2003). Social Inequality and the Reduction of Ideological Dissonance on Behalf of the System: Evidence of Enhanced System Justification among the Disadvantaged. European Journal of Social Psychology, 33, 13-36. https://doi.org/10.1002/ejsp.127

Kawachi, I., Kennedy, B. P., Lochner, K., \& Prothrow-Stith, D. (1997). Social Capital, Income Inequality, and Mortality. American Journal of Public Health, 87, 1491-1498. https://doi.org/10.2105/AJPH.87.9.1491

Kluegel, J. R., \& Smith, E. R. (1986). Beliefs about Inequality: Americans' Views of What Is and What Ought to Be. Aldine Transaction.

Kraus, M. W., Rucker, J. M., \& Richeson, J. A. (2017). Americans Misperceive Racial Economic Equality. Proceedings of the National Academy of Sciences, 114, 10324-10331. https://doi.org/10.1073/pnas.1707719114

Lenski, G. (1966). Power and Privilege: A Theory of Social Stratification. McGraw-Hill.

Norton, M. I., \& Ariely, D. (2011). Building a Better America-One Wealth Quintile at a Time. Perspectives on Psychological Science, 6, 9-12. https://doi.org/10.1177/1745691610393524

Oishi, S., Kesebir, S., \& Diener, E. (2011). Income Inequality and Happiness. Psychological Science, 22, 1095-1100. https://doi.org/10.1177/0956797611417262

Pickett, K. E., \& Wilkinson, R. G. (2010). Inequality: An Under-Acknowledged Source of Mental Illness and Distress. The British Journal of Psychiatry, 197, 426-428. https://doi.org/10.1192/bjp.bp.109.072066

Preacher, K. J., \& Hayes, A. F. (2008). Asymptotic and Resampling Strategies for Assessing and Comparing Indirect Effects in Multiple Mediator Models. Behavior Research Methods, 40, 879-891. https://doi.org/10.3758/BRM.40.3.879

Rodriguez-Bailon, R., Bratanova, B., Willis, G. B., Lopez-Rodriguez, L., Sturrock, A., \& Loughnan, S. (2017). Social Class and Ideologies of Inequality: How They Uphold Unequal Societies. Journal of Social Issues, 73, 99-116. https://doi.org/10.1111/josi.12206

Sánchez-Rodríguez, Á., Willis, G. B., \& Rodríguez-Bailón, R. (2019). Economic and Social Distance: Perceived Income Inequality Negatively Predicts an Interdeendent Self-Construal. International Journal of Psychology, 54, 117-125.

https://doi.org/10.1002/ijop.12437

Sidanius, J., \& Pratto, F. (2001). Social Dominance: An Intergroup Theory of Social Hierarchy and Oppression. Cambridge University Press.

Starmans, C., Sheskin, M., \& Bloom, P. (2017). Why People Prefer Unequal Societies. Nature Human Behaviour, 1, 1-7. https://doi.org/10.1038/s41562-017-0082

Wang, J., \& Liu, L. (2019). The Status Quo, Change and the Dynamics: Sense of Security, Sense of Gain and Sense of Happiness, and the Paths to Enhancement. Jiangsu Social Sciences, 1, 41-49.

Wang, Y., Yang, C., Hu, X., \& Chen, H. (2020). The Mediating Effect of Community 
Identity between Socioeconomic Status and Sense of Gain in Chinese Adults. International Journal of Environmental Research and Public Health, 17, 1553.

https://doi.org/10.3390/ijerph17051553

Whyte, M. K., \& Im, D. K. (2014). Is the Social Volcano Still Dormant? Trends in Chinese Attitudes toward Inequality. Social Science Research, 48, 62-76. https://doi.org/10.1016/j.ssresearch.2014.05.008

Xie, Y. (2016). Understanding Inequality in China. Chinese Journal of Sociology, 2, 327-347. https://doi.org/10.1177/2057150X16654059

Xie, Y., \& Zhou, X. (2014). Income Inequality in Today's China. Proceedings of the National Academy of Sciences, 111, 6928-6933. https://doi.org/10.1073/pnas.1403158111

Xie, Y., Thornton, A., Wang, G., \& Lai, Q. (2012). Societal Projection: Beliefs Concerning the Relationship between Development and Inequality in China. Social Science Research, 41, 1069-1084. https://doi.org/10.1016/j.ssresearch.2012.04.001 